\title{
Jejunostomy tube removed after pancreaticoduodenectomy using single-balloon endoscopy
}

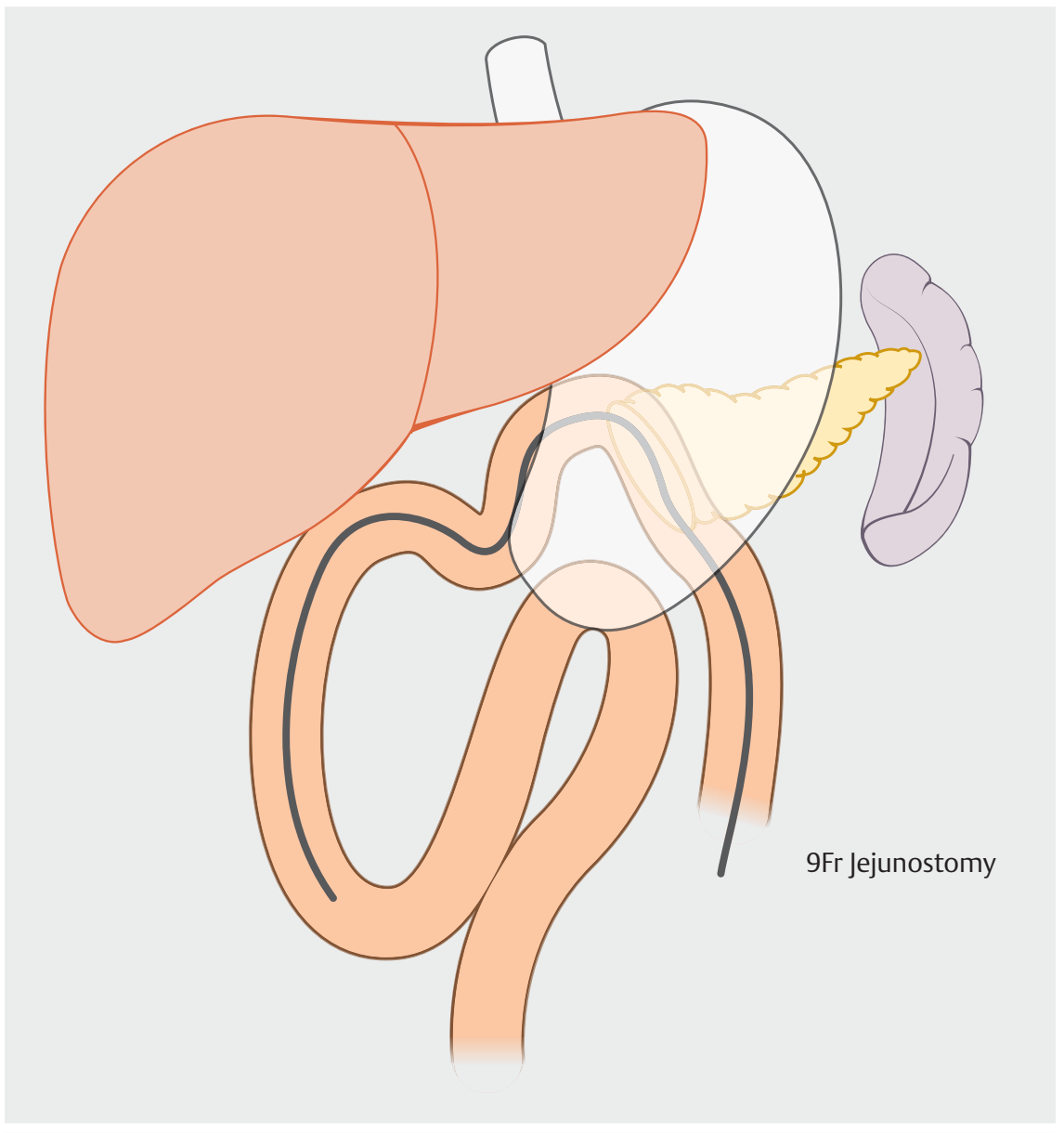

Fig. 1 The overview of the jejunostomy feeding tube placed after pancreaticoduodenectomy.

A 70-year-old woman underwent a subtotal stomach-preserving pancreaticoduodenectomy with a modified Child's reconstruction method for an intraductal papillary mucinous neoplasm. A jejunostomy feeding tube was temporarily placed ( $/$ Fig.1) but could not be removed 1 month after the operation. No abnormalities were found on X-ray ( Fig.2). Enteroscopy was deemed necessary to investigate why the tube could not be removed.

An oral single-balloon endoscopy was performed. We used the SIF TYPE Q260 endoscope (Olympus, Tokyo, Japan) to observe and evaluate the small intestine. The endoscope was inserted by efferent loop, and the jejunostomy tube was subsequently found. We found that a blue suture, thought to have been used in the pancreaticoduodenectomy, had penetrated through the tube from outside the intestinal tract, $20 \mathrm{~cm}$ on the oral side from the blind end ( $\triangleright$ Fig. 3 a). Since the length of the snare cutter was not long enough to cut the thread, the scope was changed to a $290 \mathrm{TI}$ endoscope (Olympus), leaving the overtube. Both sides of the thread were then cut off with a snare cutter ( $\triangleright$ Fig. $\mathbf{3 b}$ ), and the tube

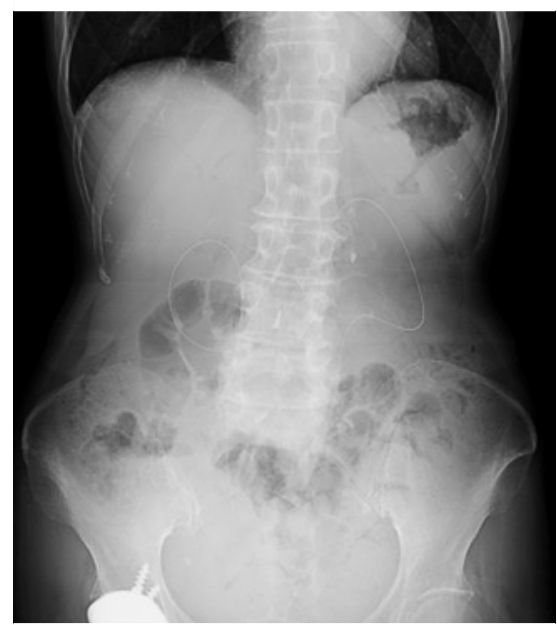

- Fig. 2 Jejunostomy tube is placed in the intestine. No abnormalities were found on X-ray.

was subsequently removed ( $\downarrow$ Video 1 , Fig. 4).

Jejunostomy tubes are commonly placed in cases of pancreaticoduodenectomy. Although complications related to feeding tubes may occur after surgery [1,2], no reports exist on the difficulty of removing such tubes because of sutures. Knowing how to deal with such complications is very important, since further operation due to complications may affect patient prognosis and should be actively avoided. In this regard, balloon endoscopy is useful for observing and treating the jejunal intestinal tract after pancreaticoduodenectomy [3]. In summary, we report the removal of jejunostomy tube placed after pancreaticoduodenectomy, by single-balloon endoscopy, thereby avoiding the risk of a reoperation.

Endoscopy_UCTN_Code_TTT_1AP_2AD

\section{Competing interests}

The authors declare that they have no conflict of interest. 


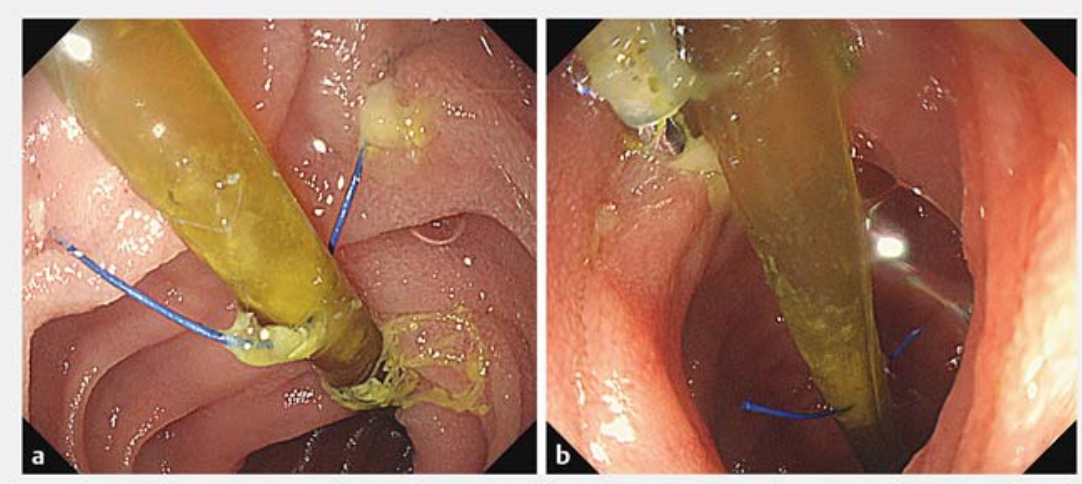

Fig. 3 Endoscopic views of the jejunostomy tube 1 month later. a A blue suture had penetrated through the jejunostomy tube from outside the intestinal tract. $\mathbf{b}$ Both sides of the thread were cut off with a snare cutter.
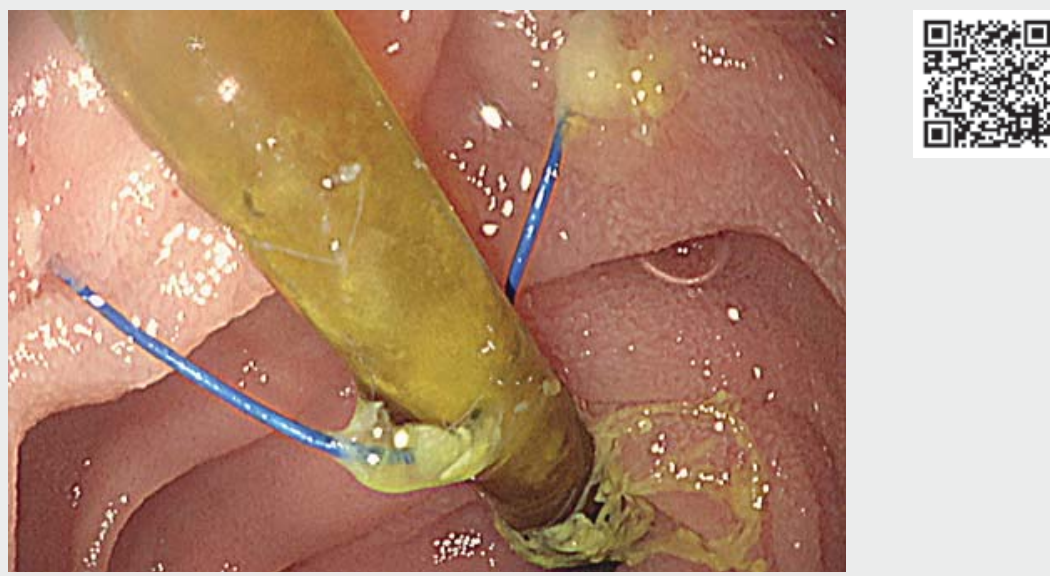

Video 1 Jejunostomy tube removed by cutting the thread with a snare cutter using a single-balloon endoscopy.

\section{The authors}

Keiichi Haga, Tomoyoshi Shibuya, Kei Nomura, Mayuko Haraikawa, Osamu Nomura, Akihito Nagahara

Department of Gastroenterology, Juntendo University School of Medicine, Bunkyo-ku, Tokyo, Japan

\section{Corresponding author}

\section{Tomoyoshi Shibuya, MD}

Department of Gastroenterology, Juntendo University School of Medicine, 2-1-1 Hongo, Bunkyo-ku, Tokyo 113-8421, Japan

Fax: +81-33-813-8862

tomoyosi@juntendo.ac.jp

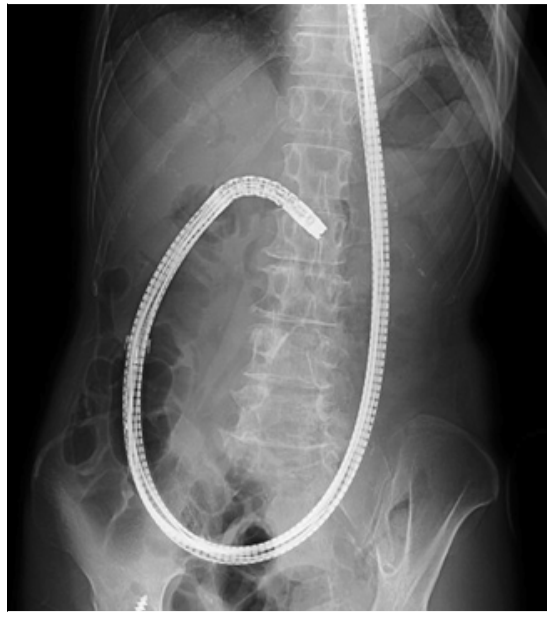

Fig. 4 X-ray after removing the jejunostomy tube.

Bibliography

Endoscopy 2022; 54: E478-E479

DOI $10.1055 / a-1630-6122$

ISSN 0013-726X

published online 1.10 .2021

(c) 2021. Thieme. All rights reserved.

Georg Thieme Verlag KG, Rüdigerstraße 14, 70469 Stuttgart, Germany

\section{ENDOSCOPY E-VIDEOS}

https://eref.thieme.de/e-videos

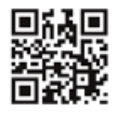

Endoscopy E-Videos is an open access online section, reporting on interesting cases and new techniques in gastroenterological endoscopy. All papers include a high quality video and all contributions are freely accessible online. Processing charges apply (currently EUR 375), discounts and wavers acc. to HINARI are available.

This section has its own submission website at https://mc.manuscriptcentral.com/e-videos 